\title{
KEABSAHAN PERKAWINAN NGEROROD (KAWIN LARI) DI DESA KELUSA, KABUPATEN GIANYAR
}

\author{
I Wayan Bayu Suta, I Nyoman Putu Budiartha, I Ketut Sukadana \\ Fakultas Hukum Univeristas Warmadewa, Denpasar-Bali, Indonesia \\ Bayu.suta2511@gmail.com, budiarthaputu59@gmail.com, sukadanaketut1966@gmail.com
}

\begin{abstract}
Abstrak
Hukum adat Bali dewasa ini mengenal dua cara melangsungkan perkawinan, yaitu kawin dengan cara memadik (meminang) dan kawin dengan cara Ngerorod (kawin lari). Apabila dalam masa pertunangan mendapat restu orangtua dan keluarga kedua belah pihak, maka akan dipilih dengan cara memadik. Sebaliknya apabila masa pertunangan dirasa kurang mendapatkan restu dari orangtua dan keluarga salah satu atau kedua belah pihak, sedangkan pasangan ini terlanjur jatuh cinta dan tidak mungkin lagi dipisahkan lagi, maka ngerorod menjadi satu-satunya cara melangsungkan perkawinan. Penelitian ini bertujuan untuk mengetahui keabsahan perkawinan Ngerorod (kawin lari) di desa Kelusa, dan untuk mengetahui penyelesaian hukum dalam perkawinan Ngerorod di desa Kelusa. Metode penelitian yang digunakan adalah metode penelitian hukum empiris dengan pendekatan sosiologi hukum. Hasil penelitian menunjukkan bahwa keabsahan perkawinan ngerorod yang biasa terjadi di desa Kelusa yaitu si laki-laki dan perempuan membuat surat pernyataan bahwa si perempuan sudah sah ada di rumah laki-yang dia cintai. Keluarga laki- laki mendatangi Bendesa Adat beserta Kelian Adat untuk membicarakan perihal perkawinan ngerorod tersebut, kemudian pihak laki-laki menjemput si perempuan sampai di depan rumahnya. Kemudian, penyelesaian hukum dalam Perkawinan Ngerorod di desa Kelusa karena si wanita masih terikat ikatan perkawinan dengan orang lain, setelah melalui sangkep (rapat) oleh prajuru desa adat memberikan sanksi adat serta diarahkan atau diwajibkan melakukan perceraian secara sah menurut ketentuan Undang-Undang.
\end{abstract}

Kata Kunci: Hukum Adat Bali; Keabsahan; Perkawinan Ngerorod.

\begin{abstract}
Today's Balinese customary law recognizes two ways to carry out a marriage, namely marrying by memadik (engaging) and marrying by means of Ngerorod (kawin lari). If during the engagement period the parents and families of both parties have the blessing, the marriage will be done by memadik. Conversely, if the engagement period does not get the blessing of the parents and family of one or both parties, while the couple has already fallen in love and it is no longer possible to be separated, then ngerorod is the only way to get married. This study aims to determine the validity of the Ngerorod marriage (kawin lari) in the village of Kelusa, and to determine the legal settlement of the Ngerorod marriage in the village of Kelusa. The research method used is an empirical legal research method with a sociology of law approach. The results showed that the legality of the ngerorod marriage that usually occurs in Kelusa village is that the man and the woman make a statement that the woman is legally in the house of the man she loves. The male family came to Bendesa Adat and Kelian Adat to discuss the ngerorod marriage, then the man picked up the woman in front of her house. Then, the legal settlement in the Ngerorod Marriage in Kelusa village was because the woman was still married to another person, after going through a sangkep (meeting) by the traditional village prajuru giving customary sanctions and being directed or obliged to legally divorce according to the provisions of the Law.
\end{abstract}

Keywords: Balinese Customary Law; Validity; Ngerorod Marriage.

\section{PENDAHULUAN}

Hukum adat memegang peranan yang sangat penting dalam mengatur hubungan antar manusia dalam kehidupan sehari-hari, termasuk dalam pengaturan perkawinan. Hukum adat Van Vollenhoven adalah kode etik yang berlaku untuk kelompok adat dan kelompok asing timur yang dikenai sanksi di satu sisi. Seringkali dikatakan bahwa hukum adat adalah hukum tanpa modifikasi dan ditujukan kepada kelompok masyarakat adat. Perkawinan menurut agama Hindu sangat mulia karena salah satu tujuan perkawinan adalah untuk mencapai tujuan niskala (keimanan), yaitu cara melepaskan orang tua dan dosa-dosa luhur (nyupat) dengan membayar tiga utang, dan ketiga utang itu 
harus dilunasi. Bayar melalui upacara, (Ritual) dilakukan sesuai dengan Hindu (filsafat) dan moralitas (moralitas) (Windia, 2017). Oleh karena itu, nikah dan melahirkan adalah perintah agama yang luhur. Bagi umat Hindu, orang percaya pada hakikat pernikahan dari waktu ke waktu.

Menurut umat Hindu, perkawinan ngerrod diyakini masih dianggap sah, dan berdasarkan pertimbangan hukum Putusan Pengadilan Negeri Denpasar Nomor 1, mengakui adanya sistem perkawinan ngerrod. 43 / PN.Dps / Pdt / 1976. Perkawinan Engelold membawa konsekuensi hukum pada perjanjian adat, yang harus didasarkan pada keyakinan agama dan prosedur administratif untuk memastikan kepastian hukum. Dalam perkawinan diharapkan keluarga tetap harmonis hingga pasangan suami istri meninggal secara terpisah. Namun yang terjadi di Desa Klusa adalah sepasang suami istri yang kawin secara sah dan memiliki keturunan hamil dengan laki-laki lain tanpa mengetahui suami (istri) sah dari perempuan tersebut, dan kemudian tanpa mengetahui laki-laki tersebut. Pernikahan rahasia. Laki-laki (suami sah), bendesa adat, kepala desa. Ini sepertinya pernikahan poliandri.

Berdasarkan uraian di atas, maka penelitian ini bertujuan untuk mengetahui keabsahan Perkawinan Ngerorod (kawin lari) di desa Kelusa, serta untuk mengetahui penyelesaian hukum dalam Perkawinan Ngerorod di desa Kelusa.

\section{METODE PENELITIAN}

Metode yang digunakan dalam penelitian ini adalah penelitian empiris dengan pendekatan pendekatan sosiologi hukum (Soekanto \& Memudji, 2003). Dalam penelitian ini menggunakan data hukum dalam bentuk data yang digunakan adalah hasil penelitian di lapangan yaitu di desa Kelusa kecamatan Payangan yang diperoleh dari kepada kepala desa, bendesa adat yang menangani langsung kasus perkawinan ngerorod (kawin lari). Bahan sekunder, penelitian kepustakaan yaitu untuk mendapatkan bahan hukum sekunder dari buku-buku literatur, jurnal-jurnal hukum, karya para sarjana, dan karya ilmiah lainnya. Pengumpulan data primer yang dipergunakan dalam penulisan skripsi ini adalah dengan wawancara dengan pihak terkait. Wawancara dilakukan dengan para informan yang ada kaitannya yaitu dengan kepala desa atau bendesa adat di Desa Kelusa Kecamatan Payangan. Adapun teknik pengumpulan data sekunder yang dipergunakan adalah teknik dengan cara studi dokumen dan pencatatan yang artinya bahan hukum yang dikumpulkan diklasifikasi sesuai dengan jenis bahan yang akan digunakan dalam pembahasan permasalahan. Adapun alasan memilih lokasi tersebut yaitu karena di Desa Kelusa yang terjadi pristiwa wanita yang belum sah bercerai secara hukum nasional dan adat tetapi sudah melangsungkan perkawinan lagi. Setelah diperoleh data-data yang berhubungan dengan permasalahan, maka data tersebut akan diolah serta secara kualitatif yaitu dengan cara mendeskripsikan data yang diperoleh dalam bentuk penjelasan dan uraian - uraian kalimat. selanjutnya dapat ditarik simpulan secara induktif yaitu suatu cara berfikir dari hal-hal yang bersifat umum lalu diambil simpulan secara khusus.

\section{HASIL PENELITIAN DAN PEMBAHASAN}

\section{Keabsahan Perkawinan Ngerorod (kawin lari) di desa Kelusa}

Pernikahan Engro Lord dapat diartikan sebagai "lari bersama", pria dan wanita yang akan menikah (biasanya diam-diam) berkumpul, meninggalkan rumah, bersembunyi dengan keluarga lain (pihak ketiga), dan mengklaim diri mereka sendiri dalam teror. Orang tua biasanya tidak mengetahui jenis pernikahan ini. Sekalipun mereka sudah menikah, orang tua berpura-pura tidak tahu, karena pernikahan lebih jarang digunakan dibanding yang lain. Cara ini diadopsi karena orang tua perempuan tidak setuju dengan hubungan anak perempuannya dengan suami laki-laki yang dituju. Terlepas dari baik atau tidaknya perilaku perkawinan ngerorod, bentuk perkawinan ini masih lazim dilakukan di Bali. Selama syarat umum perkawinan terpenuhi (misalnya batas usia tidak dilanggar atau gadis tidak dipaksa), tidak bisa disalahkan. Kalaupun perkawinan ngerorod ini beralasan dalam proses pelaksanaannya tetap harus memperhatikan norma- norma perkawinan adat (Sudiyat, 1981). Ada alasan untuk percaya bahwa pernikahan ngerorod semacam ini masih berlangsung di masa depan. Hingga saat ini keberadaan perkawinan pranikah semacam ini masih diakui keberadaannya, dan karena kebiasaan tidak bisa dihilangkan sewaktu-waktu. Ini adalah bentuk pernikahan yang paling umum.

Dalam perkembangan saat ini, meskipun pihak tersebut mendapat persetujuan orang tua, mereka tetap akan melanjutkan pernikahan ngerorod, bahkan jika mereka segera memberi tahu 
mereka bahwa mereka akan kawin lari bersama untuk menikah. Perkawinan Engrorod didasarkan pada pertimbangan ekonomi, yaitu untuk menghindari besarnya biaya yang harus ditanggung dalam perkawinan sejenis, selain itu alasannya terletak pada perbedaan kebangsaan atau kasta. Menurut agama Hindu, pernikahan ngerorod masih dianggap sah (Made, 2006). Dalam awig-awig Desa Adat Kelusa masalah perkawinan, hal ini terdapat pada palet 1 indik pawiwahan yang diatur pada pawos 57:

1. pawiwahan sane kapatutan ring desa adat kelusa, sekadi ring sor:

a. sampun kamargiang pabyakala utawi pasakapan, kasaksiang sakala niskala olih pandita utawi pinandita

b. wenten pasaksi prajuru sane mapakeling utawi ngilikitayang pawiwahan

c. sampun matengeran suaran kulkul

d. pawiwahan inucap ring ajeng sampun kailikitayang ring sang ngawewenang

2. parabian sane tan manut kadi ring ajeng sinanggeh tan patut (tan sah)

Terjemahan bebasnya:

1. Perkawinan yang diakui di Desa Adat Kelusa, seperti di bawah ini

a. Sudah dilaksanakan upacara pabyakala dan pasakapan yang disaksikan skala dan niskala oleh pemangku atau pedanda,

b. Ada para saksi prajuru yang mengetahui atau yang mencatat perkawinan,

c. Sudah menyuarakan suara kentongan

d. Perkawinan tersebut diatas sudah dibuktikan oleh pihak berwenang

2. Perkawinan yang tidak sesuai seperti yang disebutkan di atas, maka dianggap tidak sah.

Adapun hasil wawancara yang dilakukan dengan Bendesa Adat Kelusa pada hari Selasa tanggal 25 Agustus 2020, mengenai prosedur perkawinan ngerorod yang biasa terjadi dari pihak laki-laki maupun perempuan karena alasan suka sama suka tetapi tidak mendapatkan restu dari orang tua perempuan, sedangkan perempuan tersebut sudah ada di rumah laki-laki. Kemudian si laki-laki dan perempuan membuat surat pernyataan bahwa si prempuan sudah sah ada di rumah laki-yang dia cintai. Keluarga laki-laki mendatangi Bendesa Adat beserta Kelian Adat untuk membicarakan perihal perkawinan ngerorod tersebut, setelah itu keluarga laki laki menentukan hari baik untuk melakukan upacara mabiyakala dan ngemaling atau mencuri si perempuan, kemudian pihak laki-laki menjemput si perempuan sampai di depan rumahnya sekitar jam 3 pagi atau daslemah sekiranya dua orang perwakilan yang akan menjemput si perempuan, sedangkan di rumah pihak laki-laki sudah dipersiapkan banten mabyakala dan dihadiri oleh prangkat desa, prajuru, Kelian dan Pemangku. Sesampainya perempuan di rumah laki- laki langsung natab banten mebyakala jika sudah selesai Bendesa Adat beserta Kelian Adat mendatangi rumah perempuan untuk memberitahukan bahwa anaknya sudah selesai diupacarai dan memberikan surat yang dibuat dan ditandatangani oleh laki-laki dan perempuan tersebut. Karena jika belum natab banten mebyakala pihak perempuan yang tidak setuju masih bisa mengganggu gugat pihak laki-laki karena jika hanya surat saja pihak perempuan tidak akan percaya karena surat bisa dipalsukan. Jika lokasi rumah si perempuan agak jauh dari rumah si laki-laki, sebelumnya sudah dilakukan perjanjian antara perempuan dengan laki laki sampai dimana akan dijemput oleh perwakilan pihak laki-laki. Karena ngemaling harus dilakukan pada hari dimana natab mebyakala tersebut dilakukan.

\section{Penyelesaian Hukum dalam Perkawinan Ngerorod di desa Kelusa}

Tidak ada suami atau istri yang ingin pernikahan mereka gagal. Setiap orang berharap agar pernikahannya selalu penuh cinta, kebahagiaan dan kesetiaan, dan akan langgeng sampai mati dan berpisah, terutama prinsip- prinsip dalam adat Bali yang menganut sistesistem kekeluargaan yang patrilineal atau kepurusa yang diharapkan perkawinan adalah monogami (satu pasangan) kesetiaan dan tidak terceraikan, akan tetapi sering berhadapan dengan kenyataan yang berbeda, yakni ada alasanalasan yang membuat pasangan tersebut menghadapi perkawinan yang mereka perjuangkan ternyata tidak berjalan sebagaimana yang mereka cita-citakan sebelumnya dan sampai pada kenyataan untuk mengakhiri perkawinan dengan perceraian. Hal tersebut dapat dipicu dari berbagai aspek diantaranya, kesenjangan ekonomi, kekerasan dalam rumah tangga, perselingkuhan maupun KDRT. Pada sebagian masyarakat, perceraian dianggap sebagai sebuah kegagalan. Karena didalamnya terdapat pemutusan tali pernikahan yang sebelumnya dianggap sakral (William, 1991). 
Adapun masalah perceraian dalam hukum Indonesia diatur dalam Undang-Undang No 1 Tahun 1974 Tentang Perkawinan dimana diatur dalam Pasal 39 yang menyebutkan:

a. Perceraian hanya dapat dilakukan di depan Sidang Pengadilan setelah Pengadilan yang bersangkutan berusaha dan tidak berhasil mendamaikan kedua belah pihak.

b. Untuk melakukan perceraian harus ada cukup alasan bahwa antara suami istri itu tidak akan dapat rukun sebagai suami istri.

c. Tata cara perceraian di depan sidang Pengadilan diatur dalam peraturan perundangan tersebut.

Menurut Pasal 39 Ayat 2 Adapun alasan yang dapat dijadikan dasar untuk terjadinya perceraian sesuai dengan ketentuan tersebut di atas yaitu:

1. Salah satu pihak melakukan perzinahan atau menjadi pecandu alkohol, pemadam kebakaran, penjudi, dll., Yang sulit disembuhkan;

2. Salah satu pihak telah meninggalkan pihak lainnya selama dua (dua tahun) berturut-turut tanpa izin pihak lainnya, tanpa justifikasi atau alasan lain di luar kemampuannya.;

3. Salah satu pihak dijatuhi hukuman lima (lima) tahun penjara atau ditambah hukuman setelah menikah;

4. Pelecehan yang kejam atau parah oleh satu pihak ke pihak lainnya;

5. Salah satu pihak menderita cacat fisik atau sakit yang membuat tidak dapat memenuhi kewajibannya sebagai suami / istri;

6. Ada pertengkaran terus menerus antara suami dan istri, dan tidak ada harapan untuk bisa rukun lagi.

Perceraian adalah keputusan hakim atas permintaan salah satu pihak dalam pernikahan untuk membatalkan pernikahan. Intinya adalah bahwa hukum tidak mengizinkan suami dan istri untuk merundingkan perceraian secara terpisah. Dalam kasus perdata, permohonan cerai harus diajukan kepada hakim dengan cara biasa, dan sebelum itu, ketua pengadilan negeri setempat harus terlebih dahulu meminta persetujuan gugatan. Sebelum mendapat izin, hakim harus berusaha mendamaikan kedua belah pihak. Menurut Subekti \& Tjitrosudibio, perceraian adalah penghapusan perkawinan atas keputusan hakim atau permintaan salah satu pihak dalam perkawinan (Subekti \& Tjitrosudibio, 1992). pernikahan. (Simanjuntak, 2007). Menurut Dariyo (2004), perceraian adalah hasil akhir dari mengumpulkan berbagai masalah yang menumpuk selama kurun waktu tertentu, dan juga merupakan upaya terakhir yang harus diambil ketika hubungan perkawinan tidak dapat dipertahankan. Faktorfaktor yang menyebabkan perceraian (Dariyo, 2004):

a. Perselingkuhan pasangan hidup. Keberadaan pihak ketiga memang mengganggu kehidupan pernikahan. Jika tidak ada kesepakatan antara dua orang untuk menyelesaikan dan tidak saling memaafkan.

b. Tekanan kebutuhan ekonomi keluarga, Harga barang dan jasa yang semakin melonjak tinggi karena faktor krisis ekonomi negara yang belum berakhir, sementara itu gaji atau penghasilan paspasan dari suami sehingga hasilnya tidak cukup untuk memenuhi kebutuhan keluarga. Agar dapat menyelesaikan masalah itu, kemungkinan seorang istri menuntut cerai dari suaminya.

c. Karena krisis ekonomi negara yang belum berakhir, kebutuhan ekonomi keluarga tertekan, harga barang dan jasa melambung tinggi. Di saat yang sama, gaji atau pendapatan menengah suami membuat tidak mencukupi untuk memenuhi kebutuhan keluarga. Untuk mengatasi masalah ini, istri dapat menggugat cerai suaminya.

Perbedaan prinsip hidup dan agama. Berdasarkan penjabaran di atas menurut hemat penulis bagi pasangan suami istri yang sudah berketetapan hati untuk mengakhiri perkawinannya memang sebaiknya menempuh proses secara hukum melalui putusan pengadilan sehingga para pihak baik suami atau istri dapat menjalankan kehidupan kedepannya dengan baik. Hasil wawancara antara peneliti dengan Bendesa Adat Kelusa oleh pasangan suami istri yang melakukan pisah ranjang selama 7 bulan dan sepengetahuan suami sah pihak istri melakukan perkawinan lagi dengan laki- laki lain. Dimana hasil wawancara menurut bendesa adat yaitu I Nyoman Suarka hari Senin 31 Agustus 2020 menurut Bendesa Adat perkawinan yang dilakukan oleh pasangan Ni Kadek Senggu dengan Ngakan Andika tidak sah di Desa Adat Kelusa dan hukum yang berlaku di Indonesia akan tetapi perkawinan yang terjadi antara Ni Kadek Senggu dengan Ngakan Andika tidak diketahui oleh aparat desa, setelah perkawinan itu terjadi suami pertamanya I Made Widana melaporkan kasus ini ke Bendesa Adat bahwa istrinya menikah lagi dengan laki laki lain. Setelah laporan diterima oleh Bendesa Adat lalu Bendesa Adat mencari kebenaran dari laporan yang diterima setelah Bendesa Adat mengetahui 
kebenarannya itu Bendesa Adat langsung melakukan mediasi antara I Made Widana dengan Ni Kadek Senggu terkait dengan perkawinan yang dilakukan oleh Ni Kadek Senggu pada saat mediasi Ni Kadek Senggu mengajukan alasan terkait perkawinan yang sudah di lakukan Ni Kadek Senggu mengatakan bahwa dirinya sudah tidak pernah dinafkahi dan dirinya sudah bosan karena I Made Widana sering melakukan kekerasan maka dari Ni Kadek Senggu melakukan pisah ranjang dan pisah ranjang tersebut sudah terjadi selama 7 bulan pada saat pisah ranjang itu Ni Kadek Senggu melakukan hubungan baru dengan Ngakan Andika dan sampai akhirnya Ni Kadek Senggu hamil dan melakukan pernikahan secara diam- diam. Setelah Bendesa Adat menerima pengakuan dari Ni Kadek Senggu setelah itu Bendesa Adat mengadakan rapat bersama aparat desa perihal khasus yang terjadi dimana khsus itu tidak ada di dalam awig-awig. hasil dari rapat yang dilakukan oleh bendesa adat dimana pasangan Ni Kadek Senggu dengan Ngakan Andika dikenakan sanksi adat seperti:

a. ngemargiang pecaruan amance bebek belang kalung ring catus pata desa Kelusa.

b. beras cap ratu 2 karung

c. nyangu pemangku prajuru desa lan seka gong

d. dihadiri oleh prajuru ke empat banjar

e. nenten kedadosan ke pura sadurung sah palas merabian di adat

Setelah Ni Kade Senggu melaksanakan sanksi tersebut barulah Ni Kadek Senggu dan I Made Widana diarahkan atau diwajibkan melakukan perceraian secara sah menurut ketentuan UndangUndang.

\section{SIMPULAN DAN SARAN}

\section{Simpulan}

Berdasarkan hasil penelitian di atas, dapat disimpulkan bahwa keabsahan perkawinan ngerorod yang biasa terjadi di Desa Kelusa yaitu si laki-laki dan perempuan membuat surat pernyataan bahwa si perempuan sudah sah ada di rumah laki-yang dia cintai. Keluarga laki- laki mendatangi Bendesa Adat beserta Kelian Adat untuk membicarakan perihal perkawinan ngerorod tersebut, kemudian pihak laki-laki menjemput si perempuan sampai di depan rumahnya sekitar jam 3 pagi atau daslemah (sebelum matahari terbit) sekiranya dua orang perwakilan yang akan menjemput si perempuan, sedangkan di rumah pihak laki-laki sudah dipersiapkan banten mabyakala dan dihadiri oleh perangkat desa, prajuru, Kelian dan Pemangku Jika lokasi rumah si perempuan agak jauh dari rumah si laki-laki, sebelumnya sudah dilakukan perjanjian antara perempuan dengan laki laki sampai dimana akan dijemput oleh perwakilan pihak laki-laki. Karena ngemaling harus dilakukan pada hari dimana natab mebyakala tersebut dilakukan. Selanjutnya, penyelesaian Hukum dalam Perkawinan Ngerorod di Desa Kelusa karena si wanita masih terikat ikatan perkawinan dengan orang lain,setelah melalui sangkep (rapat) oleh prajuru desa adat memberikan sanksi adat serta diarahkan atau diwajibkan melakukan perceraian secara sah menurut ketentuan Undang-Undang.

\section{Saran}

Berdasarkan atas simpulan tersebut diatas dapat disarankan berbagai hal, yakni bagi masyarakat yang melakukan perkawinan itu, hendaknya dilakukan sesuai dengan hukum yang berlaku baik hukum nasional dan hukum adat. Hendaknya, prajuru adat pula tidak gegabah dan harus lebih cermat dalam mengamati status seseorang yang akan melangsungkan perkawinan.

\section{DAFTAR PUSTAKA}

Dariyo, A. (2004). Memahami Psikologi Perceraian dalam Kehidupan Kekeluargaan. Jurnal Psikologi, 2(2), 94 100.

Made, S. A. N. (2006). Upacara Manusa Yadnya, Pemerintah Daerah Provinsi Bali. Bali: Pemerintah Daerah Provinsi Bali.

Simanjuntak, P. N. H. (2007). Pokok-Pokok Hukum Perdata Indonesia. Jakarta: Pustaka Djambata.

Soekanto, S., \& Memudji, S. (2003). Penelitian Hukum Empiris. Jakarta: UI Press.

Subekti, R., \& Tjitrosudibio, R. (1992). Kitab Undang-Undang Hukum Perdata: Burgelijk Wetboek: Dengan Tambahan Undang-Undang Pokok Agraria dan Undang-Undang Perkawinan. Jakarta: Pradnya Paramita.

Sudiyat, I. (1981). Hukum Adat Sketsa Asas. Yogyakarta: Liberty.

William, J. G. (1991). Sosiologi Keluarga. Jakarta: Radar Jaya Offset.

Windia, W. P. (2017). Hukum Adat Bali: Aneka Kasus dan Penyelesaiaannya. Denpasar: Aksara Bali. 